\title{
Use of angioembolization in urology: a review
}

\author{
Kirkpatrick B. Fergus ${ }^{1}$, Nima Baradaran ${ }^{1}$, Anas Tresh ${ }^{1}$, Miles B. Conrad ${ }^{2}$, Benjamin N. Breyer ${ }^{1,3}$ \\ ${ }^{1}$ Department of Urology, ${ }^{2}$ Department of Radiology and Biomedical Imaging, ${ }^{3}$ Department of Biostatistics and Epidemiology, University of \\ California-San Francisco, San Francisco, CA, USA \\ Contributions: (I) Conception and design: All authors; (II) Administrative support: All authors; (III) Provision of study material or patients: None; \\ (IV) Collection and assembly of data: KB Fergus; (V) Data analysis and interpretation: All authors; (VI) Manuscript writing: All authors; (VII) Final \\ approval of manuscript: All authors. \\ Correspondence to: Dr. Benjamin N. Breyer, MD, MAS, FACS. Associate Professor of Urology, University of California-San Francisco, Zuckerberg \\ San Francisco General Hospital and Trauma Center, 1001 Potrero Suite 3A, San Francisco, CA 94110, USA. Email: Benjamin.Breyer@ucsf.edu.
}

\begin{abstract}
This review discusses current and developing indications for angioembolization (AE) techniques in urology cases, including trauma and non-trauma uses for kidney, prostate, and bladder conditions. AE methods, complications and technical and clinical outcomes are outlined for each indication for the purpose of aiding urologists in selecting ideal candidates for this procedure.
\end{abstract}

Keywords: Angioembolization (AE); benign prostatic hyperplasia (BPH); embolization; trauma

Submitted Mar 11, 2018. Accepted for publication May 14, 2018.

doi: $10.21037 /$ tau.2018.05.12

View this article at: http://dx.doi.org/10.21037/tau.2018.05.12

\section{Introduction: role of angioembolization (AE) in urology}

$\mathrm{AE}$ is a minimally invasive procedure in which interventional radiologists access peripheral arteries under image guidance to selectively occlude the blood supply of target tissues. It has become an increasingly important tool in the arsenal of treatments for urological conditions since its origin in the 1970's. The role of AE is established in the treatment of hemorrhagic emergencies in urology and recently it has been investigated in other pathologies such as in $\mathrm{BPH}$ and prostate cancer. Urologists should be familiar with $\mathrm{AE}$ and its clinical indications, as well as its risks, benefits, and alternatives. This critical review aims to present the current state of $\mathrm{AE}$ techniques used in urological cases for the benefit of the practicing urologist.

\section{AE methods}

Access for renal artery embolization, one of the more established urologic indications, is typically gained through the common femoral artery, or left radial artery. The brachial or axillary arteries can be used as back-up options (1). Ultrasound is often used to puncture the artery with a needle allowing advancement of a guide wire and sheath. A 5 French catheter is then advanced into the target organ artery (e.g., renal) and through this, a microcatheter and wire are used to select distal branches. Embolic agents are loaded into the catheter and injected or pushed into the target artery. Embolization agents can be categorized as coils, plugs and particles and either temporary or permanent. Modern coils and plugs are made of MRI compatible metal alloys such as nitinol. Particles, can be selected based on their size range (e.g., 300-500 $\mu \mathrm{m}$ ), shape, and pliability. The most commonly used temporary embolic agent is gelfoam which can be molded into injectable torpedo like pledgets or agitated to create a particle slurry. A summary of typical embolic agents used in a given procedure can be found in Figure 1 .

\section{$A E$ in renal trauma}

In broad terms, non-invasive strategies are preferred in hemodynamically stable renal trauma patients. Surgical interventions as well as $\mathrm{AE}$ are reserved for cases of persistent bleeding $(6,7)$. Breyer $e t$ al. previously discussed a treatment algorithm for management of renal trauma (Figure 2), which complements current American Urological 


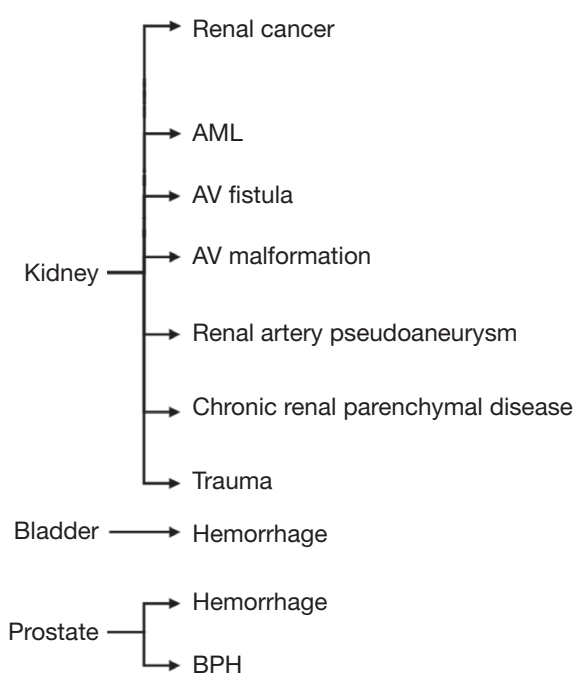

Partial or total nephrectomy: alcohol + [gelfoam; lipiodol; PVA particles; or synthetic microspheres]

Only in total nephrectomy: coil embolization

Microcoils, non-absorbable particles, PVA particles, absolute dehydrated ethanol, sotradecol, N-butyl-2-cyanoacrylate (glue)

Microcoils

N-butyl-2-cyanoacrylate (glue), onyx, sotradecol/ $\mathrm{CO}_{2}$ foam, balloon, coils

Microcoils, stents

Liquids \& particulates (small vessels), coils (large vessels)

Gelfoam (small vessels), PVA particles \& microcoils (large vessels)

Microspheres, PVA particles, N-butyl-2-cyanoacrylate (glue), coil

Microspheres, PVA particles, N-butyl-2-cyanoacrylate (glue), coil

Microspheres, PVA particles, coils

Figure 1 Common embolic agents in angioembolization procedures (1-5). For each of the urologic indications for angioembolization, common embolic agents are listed, though the list is not exhaustive.

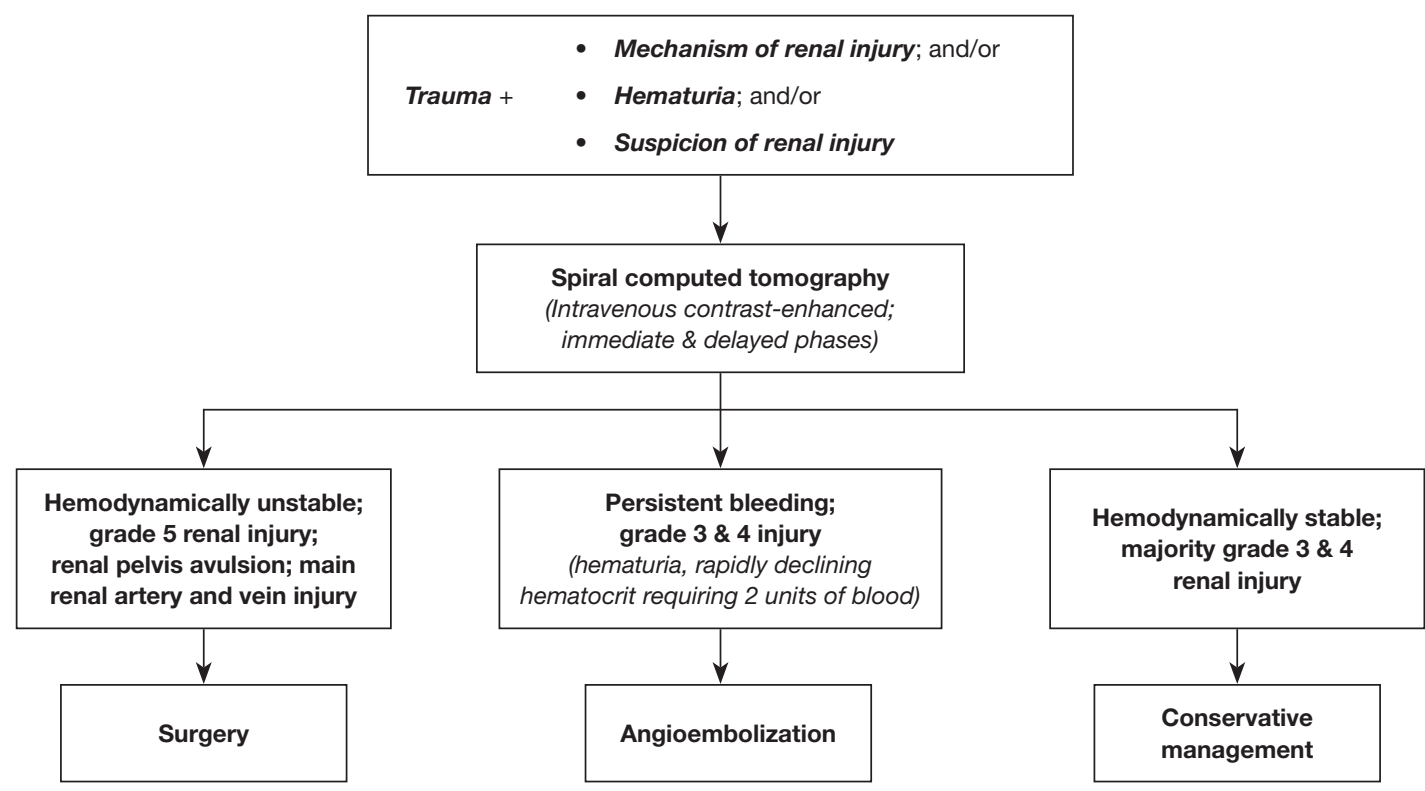

Figure 2 Minimally invasive techniques for acute renal hemorrhage. This is a management algorithm for renal trauma produced by Breyer et al. 2008. Reproduced with permission from Dr. Benjamin Breyer and Elsevier Publishing Company.

Association (AUA) Guidelines $(6,7)$. The first step is intravenous contrast-enhanced CT imaging with delayed and immediate phases for diagnostic purposes, which provides the renal trauma grade and a visual of the renal arteries, veins, and parenchyma. Management strategies are contingent on the trauma grade, the integrity of renal vascular structures, and the hemodynamic stability of the patient. Hemodynamically stable patients are managed with non-invasive strategies including observation, rest and serial hematocrit measurements according to Breyer et al. and AUA Guidelines (grade B evidence strength) $(6,7)$. On the other hand, patients with persistent bleeding may ultimately require intervention. Further, hemodynamically unstable patients that do not respond-or transiently 


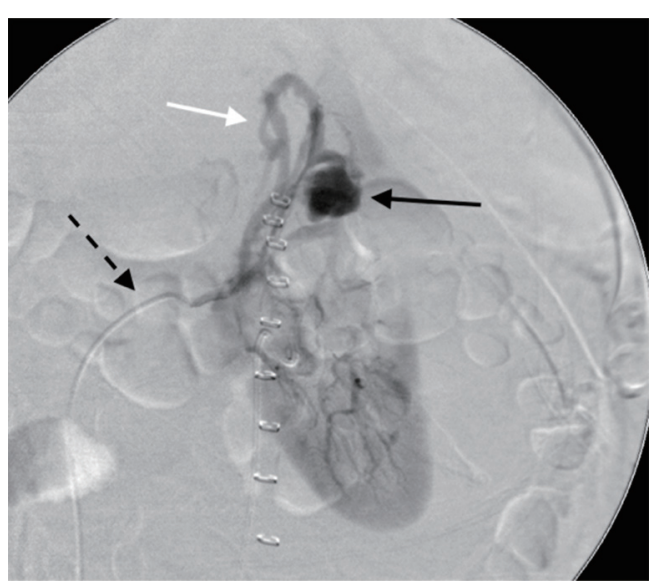

Figure 3 Renal pseudoaneurysm and arteriovenous fistula (AVF). Selective left renal angiogram demonstrates catheter in the left renal artery (dashed arrow). Superior pole renal pseudoaneurysm is present (black arrow) with early draining vein (white arrow) indicating that AVF is also present. Renal pseudoaneurysms often occur together with AVF. This was treated with coil embolization.

respond-to resuscitation require immediate intervention (Grade B evidence strength) (6). According to Breyer et al., indications for surgery over $\mathrm{AE}$ techniques in hemodynamically unstable patients include grade $\mathrm{V}$ renal injury, avulsion of the renal pelvis, and damage to the main renal artery and vein (though renal artery stent is another option for this indication) (7).

Primary AE interventions are ideally suited for patients with persistent bleeding, lower than grade $\mathrm{V}$ injury, and an intact main renal artery and vein (7). Studies of AE techniques in this patient population found final technical and clinical success rates above $90 \%$ (7-9). For patients with grade $\mathrm{V}$ renal injury, two large studies found mixed evidence of success $(7,9)$. It is reasonable to anticipate subsequent interventions when using $\mathrm{AE}$ to treat grade $\mathrm{V}$ renal injuries, and as such it is currently not recommended as first-line treatment, especially in context of currently available surgical interventions (7).

All cases of conservatively managed renal trauma should be monitored and observed for a change in hemodynamic status, as delayed hemorrhage such as from a pseudoaneurysm is possible $(10,11)$. As one prospective study found, $18 \%$ of those treated with non-operative intent ultimately needed surgical intervention (12). In these cases of delayed hemorrhage, $\mathrm{AE}$ is a good first-line choice of treatment.

\section{Iatrogenic injuries}

$\mathrm{AE}$ techniques are also used successfully in the case of iatrogenic vascular injury of the kidney to cease or abate resultant bleeding (13). Iatrogenic vascular injuries consist of intraparenchymal pseudoaneurysms, intraoperative/ post-operative hemorrhage, or arteriovenous (AV) fistulas. Pseudoaneurysms are arterial perforations that are contained by parenchyma or adventitia and are prone to rupture. AV fistulas are connections between arteries and veins (14). Frequently AV fistula is seen in the presence of a pseudoaneurysm (Figure 3). Pseudoaneurysms and AV fistulas can decompress into the collecting system causing hematuria. Iatrogenic causes of these phenomena can be related to surgeries or procedures, including partial nephrectomy, renal biopsy, guidewire arterial perforation in angiography or renal stenting, or percutaneous nephrolithotomy (13).

Complications due to partial nephrectomy are among the most common iatrogenic renal vascular injuries for which $\mathrm{AE}$ is indicated. A large, multi-center retrospective study of 998 minimally invasive partial nephrectomy procedures found that approximately $2 \%$ resulted in iatrogenic vascular injury (15). A study of 1,425 patients in Germany undergoing partial nephrectomy found similar results, with $2.7 \%$ resulting in pseudoaneurysm or arteriovenous fistula (16). Pseudoaneurysms, though rare, usually present around 14.9 days after surgery (17). Patients with pseudoaneurysms experience gross hematuria and flank pain, and sometimes dizziness and fever. AE has been shown to be safe and effective with success rates as high as $96-100 \%(17-19)$. Although vascular injury can occur in $8 \%$ of cases after renal biopsy, as little as $1 \%$ may require intervention with selective AE, with similar findings for complications of percutaneous nephrolithotomy and guidewire perforation of the renal artery $(13,20-23)$.

\section{Non-trauma indications for renal AE}

\section{Angiomyolipoma (AML)}

In the case of renal AMLs, both renal AE and surgical excision are efficacious treatments for patients experiencing pain or hemorrhage, particularly if symptoms are accompanying a tumor $>4 \mathrm{~cm}(24,25)$. Other minimally invasive treatment modalities include laparoscopic/ percutaneous ablation (including radiofrequency ablation, microwave ablation, and cryoablation) as well as robotassisted laparoscopic partial nephrectomy (26). AMLs are 
relatively rare, occurring with an incidence of $0.1-0.2 \%$ (27). The current literature on the topic is thus based on relatively smaller sample sizes. In the absence of guidelines or randomized controlled trials, urologists must first consider the following: number of tumors, size and location, efficacy and risks, co-morbidities, renal function of the patient, and patient/provider preference (28). In one retrospective study from 1999-2009 in Vancouver, surgery was more common than renal $\mathrm{AE}$ overall (42 vs. 17 cases), though renal $\mathrm{AE}$ was more common in the case of multifocal AML (35\% vs. $7 \%$ ) and in acute hemorrhage (50\% vs. $15 \%$ ) (28). At our institution, AML embolization is performed with a mixture of high concentration ethanol and lipiodol. This procedure can be challenging, as one study of 17 patients with AML reported aneurysm rupture with extravasation can occur, sometimes requiring a second embolization (27). In rare cases, pregnant patients can experience growth and rupture of AMLs during pregnancy, which is hypothesized to be associated with hormone stimulation (24). Cases of managing these patients with selective $\mathrm{AE}$ exist, though the procedure should be used with caution (24).

\section{Renal cancer}

There is a role for renal $\mathrm{AE}$ in renal malignancy as an adjunct to surgery. An important advantage of occluding the blood supply to the point of infarction is reducing tumor dimension, bulk and burden prior to partial or total nephrectomy (29). It is also well-established that AE prior to surgery reduces intraoperative blood loss, and it is reported that the resultant plane of edema facilitates resection with a peak effect occurring at 72 hours (29-31). In fact, a retrospective case-control study of pre-operative $\mathrm{AE}$ versus surgery alone controls matched for age, sex and tumor stage, size and grade found the treatment patients had increased 5 - and 10 -year survival (62\% and $47 \%$ respectively) when compared to no treatment (35\% and $23 \%$ ) (32). In the event of spontaneous uncontrolled bleeding originating in the malignant renal mass, embolization is both safe and effective. Another important use of AE is palliation for unresectable malignancy as it can minimizes tumor bulk and size and reduces hematuria and flank pain for symptomatic relief (29). However, the procedure is not without drawbacks, as many patients experience post-infarction syndrome in which fever, nausea, vomiting and pain occur 1-3 days post-procedure (33). More serious complications, though rare, include embolization of unintended vessels and tubular necrosis (33).

\section{Arteriovenous malformation \& fistula}

Although arteriovenous (AV) malformations are typically due to trauma and can result from iatrogenic insults, other rare congenital forms exist such as hemangiomas. The clinical presentation of arteriovenous malformations includes flank pain, perinephric hematoma, gross hematuria, hypertension, or high output cardiac failure (34). AV malformations are difficult to definitively cure, and patients may require intermittent treatment throughout their lives (5). These cases can be technically challenging for interventional radiologists as $\mathrm{AV}$ malformations often have high rate of blood flow. However, embolization techniques have been shown to be safe and effective in treating AV malformations, including those of congenital origin (35-37). Technical and clinical success rates vary from $67-87 \%(35,38)$. Smaller studies report higher technical and clinical success rates $(36,39)$. Specifically for renal arteriovenous fistulas, embolization intervention is lasting, with one study showing a cease of symptoms over a 10-year study period (40).

\section{Parenchymal disease: polycystic kidney disease \& end-stage renal disease}

Reports of renal parenchymal indications are predominantly outside of the United States. In patients with severe flank pain in the context of end-stage renal disease (ESRD), embolization has been proposed as an alternative to nephrectomy (41). It has also been proposed to reduce kidney size and make transplantation more feasible. Cyst diameter expansion in ADPKD is linked to increased vascular supply via angiogenesis, which is one of the reasons why embolization has been successful in renal volume reduction in numerous observational studies (41). For patients with ESRD, complete occlusion of renal artery starting with the peripheral vessels and moving to larger vessels has been shown in small-sample studies to be a safe and effective alternative to nephrectomy $(5,42-44)$.

\section{Non-renal urology indications for AE}

\section{Benign prostatic byperplasia (BPH)}

Since the initial case reports of treating BPH with prostate artery embolization (PAE) in 2010 (45), several studies have found it to be safe and efficacious (46). This 
procedure involves selective cannulation of the bilateral prostatic arteries and injection of microspheres into each side to achieve stasis in the prostatic arteries. To date, there are two short term prospective trials comparing PAE to transurethral resection of the prostate (TURP). These demonstrate that both procedures resulted in similar symptom improvement. A 2014 trial showed that TURP yielded greater improvement in symptoms and urodynamic parameters (47). PAE had a lower technical and clinical success rate $(94.7 \%$ and $90.6 \%$ respectively) than TURP (100\% and 96.1\%) (47). A more recent trial using a modified embolization technique demonstrated similar symptomatic improvement between both groups but the TURP group demonstrated better urodynamic improvement and more adverse sequelae than the PAE group (48).

There is no long term clinical trial comparing PAE and TURP. One prospective cohort study of 630 patients receiving PAE for $\mathrm{BPH}$ found $76.3 \%$ had clinical success over medium term follow-up ( $>3-6.5$ years), with none of their patients reporting urinary incontinence or sexual dysfunction (49). At 36 months in this study, mean improvement in IPSS was 12.1 points $(\mathrm{SD}=8.6)$ and mean Qmax improvement was $3.21 \mathrm{~mL} / \mathrm{min}(\mathrm{SD}=10.3)(49)$. Moreover, the vast majority of studies report prostatic $\mathrm{AE}$ has no adverse effect on erectile function (50). Major complications do occur in rare cases, including retropubic, urethral, or perineal pain, hematuria, and intraluminal necrotic prostate tissue $(51,52)$. Numerous small-sample, single-arm trials have demonstrated safety and short-term clinical success of prostatic $\mathrm{AE}$ in the treatment of $\mathrm{BPH}$ (53-57). A few studies have found initial efficacy in treating large-prostate $\mathrm{BPH}$, defined as $>90 \mathrm{~g}$ or $>80 \mathrm{~mL}(56,58-60)$. Candidates for prostatic AE typically have isolated $\mathrm{BPH}$ without underlying malignancy, coagulopathy, atherosclerosis, or dysfunction of the bladder, urethra, sphincters, or the innervation of these structures $(2,61)$.

\section{Bladder \& prostate hemorrbage}

Selective arterial embolization controls life-threatening bleeding in the case of persistent hematuria or frank hemorrhage of the bladder or prostate. It is considered to be a minimally invasive alternative to surgery when conservative management fails (4). Delgal et al. conducted a retrospective cohort study of 20 patients with bladder and/ or prostate hemorrhage that received $\mathrm{AE}$ treatments and found a technical success rate of $90 \%$ (62). AE has also been used successfully in the treatment of hemorrhagic cystitis, including after hematopoietic stem cell transplantation $(63,64)$. These techniques are also used in the treatment of bleeding secondary to radical prostatectomy (65). In the rare condition of arterial-ureteral fistulas with failed endovascular stenting, case reports of successful ureteral stump coil AE methods exist though efficacy has not been demonstrated $(66,67)$.

\section{High flow priapism}

Although conservative management is first-line, a series of cases using $\mathrm{AE}$ techniques to manage high flow priapism exists in the literature. Temporary occlusive agents are preferred to preserve erectile function, with some physicians reporting the use of autologous blood clots (68). In a multicenter study of 27 patients receiving embolization for high flow priapism, the procedure achieved $89 \%$ durable clinical success on the first attempt (68). Reduced sexual function is the primary adverse effect of interest, with small sample observational studies reporting $19-20 \%$ had reduced erection quality after the procedure $(68,69)$. Preliminary estimates of recurrence rates are between $30-40 \%(70,71)$.

\section{Outcomes}

Technical and clinical success rates vary by procedure, and are summarized in Table 1. Post-infarction syndrome (flank pain, nausea and vomiting) is common but resolves within days, and major complications are rare. Minor complications include fever and leukocytosis and are selflimited (75).

Contrast-induced acute kidney injury (AKI) is a possible risk in all patient populations. Though this iatrogenic cause of AKI may occur in as much as $5 \%$ of patients with normal renal function, it is more common among those with reduced renal function or diabetic nephropathy (76). Methods to reduce the risk of this condition include sparing use of contrast-requiring procedures, thorough renal function assessment, adequate hydration with isotonic solution, and pharmacologic prevention strategies such as acetylcysteine and fenoldopam (77-79).

\section{Cost}

An important consideration in the age of "high value care" is the absolute cost of AE. Few studies have reported the cost of $\mathrm{AE}$ in the context of urological cases. However, one 


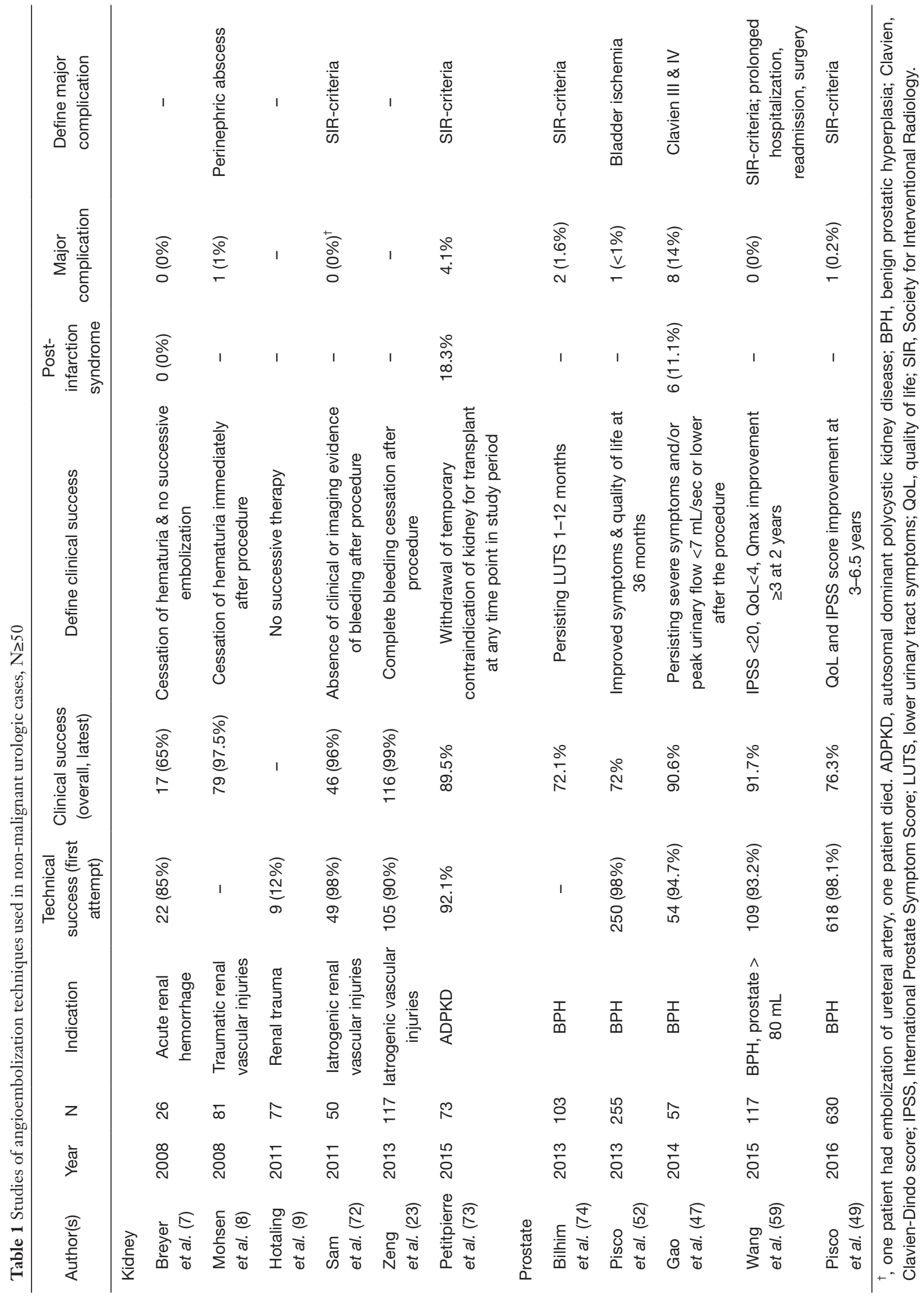


large, multi-center retrospective study found the total cost of uterine artery embolization in the treatment of fibroids was lower when compared to hysterectomy (80). According to a recent study, prostatic arterial embolization costs $\$ 1,667.10$ on average, which the authors compared to the $\$ 2,153.64$ cost of TURP (81). On the other hand, a study of non-surgical management of blunt splenic injury found the total hospital cost of embolization to be similar to that of surgery (82). More research is necessary to determine the procedural costs, total hospital costs, and cost-effectiveness of $\mathrm{AE}$ used in urological cases.

\section{Conclusions}

$\mathrm{AE}$ techniques can be employed in a variety of urologic cases, with a series of potential new indications currently under investigation. Although $\mathrm{AE}$ is well established in treating renal indications, more evidence is needed to explore the safety and efficacy of other applications such as treating BPH. Though reports of technical and clinical success rates vary across the literature, the majority of procedures across indications are successful with only minor complications. However, the clinical context for these various indications is important, and Urologists are well suited to make first-line management decisions regarding patient selection for AE procedures. Urologists will thus benefit from knowing the reported outcomes for each of these procedures as it will facilitate more informed discussions with their patients when deciding on a referral. More research is needed to explore the overlap between $\mathrm{AE}$ and more traditional urology surgical interventions.

\section{Acknowledgements}

Funding: This work was supported by the National Center for Advancing Translational Sciences, National Institutes of Health [UCSF-CTSI Grant Number TL1 TR001871 to KB Fergus]. The project was also supported by Anita and Kevan Del Grande and Russell and Sara Hirsch.

\section{Footnote}

Conflicts of Interest: The authors have no conflicts of interest to declare.

Disclaimer: The contents are solely the responsibility of the authors and do not necessarily represent the official views of the National Institutes of Health.

\section{References}

1. Sauk S, Zuckerman DA. Renal artery embolization. Semin Intervent Radiol 2011;28:396-406.

2. Carnevale FC, Antunes AA. Prostatic artery embolization for enlarged prostates due to benign prostatic hyperplasia. How I do it. Cardiovasc Intervent Radiol 2013;36:1452-63.

3. Bhatia S, Sinha V, Bordegaray M, et al. Role of Coil Embolization during Prostatic Artery Embolization: Incidence, Indications, and Safety Profile. J Vasc Interv Radiol 2017;28:656-664.e3.

4. Loffroy R, Pottecher P, Cherblanc V, et al. Current role of transcatheter arterial embolization for bladder and prostate hemorrhage. Diagn Interv Imaging 2014;95:1027-34.

5. Ginat DT, Saad WE, Turba UC. Transcatheter renal artery embolization: clinical applications and techniques. Tech Vasc Interv Radiol 2009;12:224-39.

6. Morey AF, Brandes S, Dugi DD, et al. Urotrauma: AUA guideline. J Urol 2014;192:327-35.

7. Breyer BN, McAninch JW, Elliott SP, et al. Minimally invasive endovascular techniques to treat acute renal hemorrhage. J Urol 2008;179:2248-52; discussion 2253.

8. Mohsen T, El-Assmy A, El-Diasty T. Long-term functional and morphological effects of transcatheter arterial embolization of traumatic renal vascular injury. BJU Int 2008;101:473-7.

9. Hotaling JM, Sorensen MD, Smith TG 3rd, et al. Analysis of diagnostic angiography and angioembolization in the acute management of renal trauma using a national data set. J Urol 2011;185:1316-20.

10. Lee DG, Lee SJ. Delayed hemorrhage from a pseudoaneurysm after blunt renal trauma. Int J Urol 2005;12:909-11.

11. Miller DC, Forauer A, Faerber GJ. Successful angioembolization of renal artery pseudoaneurysms after blunt abdominal trauma. Urology 2002;59:444.

12. Lanchon C, Fiard G, Arnoux V, et al. High Grade Blunt Renal Trauma: Predictors of Surgery and Long-Term Outcomes of Conservative Management. A Prospective Single Center Study. J Urol 2016;195:106-11.

13. Ierardi AM, Floridi C, Fontana F, et al. Transcatheter embolisation of iatrogenic renal vascular injuries. Radiol Med 2014;119:261-8.

14. Ngo TC, Lee JJ, Gonzalgo ML. Renal pseudoaneurysm: an overview. Nat Rev Urol 2010;7:619.

15. Hyams ES, Pierorazio P, Proteek O, et al. Iatrogenic vascular lesions after minimally invasive partial nephrectomy: a multi-institutional study of clinical and 
renal functional outcomes. Urology 2011;78:820-6.

16. Strobl FF, D'Anastasi M, Hinzpeter R, et al. Renal Pseudoaneurysms and Arteriovenous Fistulas as a Complication of Nephron-Sparing Partial Nephrectomy:Technical and Functional Outcomes of Patients Treated With Selective Microcoil Embolization During a Ten-Year Period. Rofo 2016;188:188-94.

17. Jain S, Nyirenda T, Yates J, et al. Incidence of renal artery pseudoaneurysm following open and minimally invasive partial nephrectomy: a systematic review and comparative analysis. J Urol 2013;189:1643-8.

18. Netsch C, Bruning R, Bach T, et al. Management of renal artery pseudoaneurysm after partial nephrectomy. World J Urol 2010;28:519-24.

19. Shapiro EY, Hakimi AA, Hyams ES, et al. Renal artery pseudoaneurysm following laparoscopic partial nephrectomy. Urology 2009;74:819-23.

20. Grenier N, Petitpierre F, Le Bras Y, et al. Renal embolization. Nephrol Ther 2016;12 Suppl 1:S139-43.

21. Aminsharifi A, Irani D, Eslahi A. Massive hemorrhage after percutaneous nephrolithotomy:saving the kidney when angioembolization has failed or is unavailable. Int J Surg 2014;12:872-6.

22. Hübsch PJ, Mostbeck G, Barton PP, et al. Evaluation of arteriovenous fistulas and pseudoaneurysms in renal allografts following percutaneous needle biopsy. Color - coded Doppler sonography versus duplex Doppler sonography. J Ultrasound Med 1990;9:95-100.

23. Zeng G, Zhao Z, Wan S, et al. Failure of initial renal arterial embolization for severe post-percutaneous nephrolithotomy hemorrhage: a multicenter study of risk factors. J Urol 2013;190:2133-8.

24. Khaitan A, Hemal AK, Seth A, et al. Management of renal angiomyolipoma in complex clinical situations. Urol Int 2001;67:28-33.

25. Oesterling JE, Fishman EK, Goldman SM, et al. The management of renal angiomyolipoma. J Urol 1986;135:1121-4.

26. Sivalingam S, Nakada SY. Contemporary minimally invasive treatment options for renal angiomyolipomas. Curr Urol Rep 2013;14:147-53.

27. Lenton J, Kessel D, Watkinson A. Embolization of renal angiomyolipoma: immediate complications and long-term outcomes. Clin Radiol 2008;63:864-70.

28. Faddegon S, So A. Treatment of angiomyolipoma at a tertiary care centre:the decision between surgery and angioembolization. Can Urol Assoc J 2011;5:E138-41.

29. Ginat DT, Saad WE, Turba UC. Transcatheter renal artery embolization for management of renal and adrenal tumors. Tech Vasc Interv Radiol 2010;13:75-88.

30. Bakal CW, Cynamon J, Lakritz PS, et al. Value of preoperative renal artery embolization in reducing blood transfusion requirements during nephrectomy for renal cell carcinoma. J Vasc Interv Radiol 1993;4:727-31.

31. Wallace S, Chuang VP, Swanson D, et al. Embolization of renal carcinoma. Radiology 1981;138:563-70.

32. Zielinski H, Szmigielski S, Petrovich Z. Comparison of preoperative embolization followed by radical nephrectomy with radical nephrectomy alone for renal cell carcinoma. Am J Clin Oncol 2000;23:6-12.

33. Kalman D, Varenhorst E. The role of arterial embolization in renal cell carcinoma. Scandinavian journal of urology and nephrology 1999;33:162-70.

34. Cura M, Elmerhi F, Suri R, et al. Vascular malformations and arteriovenous fistulas of the kidney. Acta Radiol 2010;51:144-9.

35. Eom HJ, Shin JH, Cho YJ, et al. Transarterial embolisation of renal arteriovenous malformation: safety and efficacy in 24 patients with follow-up. Clin Radiol 2015;70:1177-84.

36. Murata S, Onozawa S, Nakazawa K, et al. Endovascular embolization strategy for renal arteriovenous malformations. Acta Radiol 2014;55:71-7.

37. Zhang B, Jiang ZB, Huang MS, et al. The role of transarterial embolization in the management of hematuria secondary to congenital renal arteriovenous malformations. Urol Int 2013;91:285-90.

38. Takebayashi S, Hosaka M, Kubota Y, et al. Transarterial embolization and ablation of renal arteriovenous malformations: efficacy and damages in 30 patients with long-term follow up. J Urol 1998;159:696-701.

39. Hwang JH, Do YS, Park KB, et al. Embolization of Congenital Renal Arteriovenous Malformations Using Ethanol and Coil Depending on Angiographic Types. J Vasc Interv Radiol 2017;28:64-70.

40. Nassiri N, Dudiy Y, Carroccio A, et al. Transarterial treatment of congenital renal arteriovenous fistulas. J Vasc Surg 2013;58:1310-5.

41. Guler S, Cimen S, Hurton S, et al. Diagnosis and Treatment Modalities of Symptomatic Polycystic Kidney Disease. In: Li X. editor. Polycystic Kidney Disease. Brisbane (AU): Codon Publications Copyright: The Authors, 2015.

42. Golwyn DH Jr, Routh WD, Chen MY, et al. Percutaneous transcatheter renal ablation with absolute ethanol for uncontrolled hypertension or nephrotic syndrome: results in 11 patients with end-stage renal disease. J Vasc Interv 
Radiol 1997;8:527-33.

43. Keller FS, Coyle M, Rosch J, et al. Percutaneous renal ablation in patients with end-stage renal disease: alternative to surgical nephrectomy. Radiology 1986;159:447-51.

44. Hom D, Eiley D, Lumerman JH, et al. Complete renal embolization as an alternative to nephrectomy. J Urol 1999;161:24-7.

45. Carnevale FC, Antunes AA, da Motta Leal Filho JM, et al. Prostatic Artery Embolization as a Primary Treatment for Benign Prostatic Hyperplasia: Preliminary Results in Two Patients. Cardiovasc Intervent Radiol 2010;33:355-61.

46. McWilliams JP, Kuo MD, Rose SC, et al. Society of Interventional Radiology position statement: prostate artery embolization for treatment of benign disease of the prostate. J Vasc Interv Radiol 2014;25:1349-51.

47. Gao YA, Huang Y, Zhang R, et al. Benign prostatic hyperplasia: prostatic arterial embolization versus transurethral resection of the prostate--a prospective, randomized, and controlled clinical trial. Radiology 2014;270:920-8.

48. Carnevale FC, Iscaife A, Yoshinaga EM, et al. Transurethral Resection of the Prostate (TURP) Versus Original and PErFec'TED Prostate Artery Embolization (PAE) Due to Benign Prostatic Hyperplasia (BPH): Preliminary Results of a Single Center, Prospective, Urodynamic-Controlled Analysis. Cardiovasc Intervent Radiol 2016;39:44-52.

49. Pisco JM, Bilhim T, Pinheiro LC, et al. Medium- and Long-Term Outcome of Prostate Artery Embolization for Patients with Benign Prostatic Hyperplasia: Results in 630 Patients. J Vasc Interv Radiol 2016;27:1115-22.

50. Uflacker A, Haskal ZJ, Bilhim T, et al. Meta-Analysis of Prostatic Artery Embolization for Benign Prostatic Hyperplasia. J Vasc Interv Radiol 2016;27:1686-1697.e8.

51. Feng S, Tian Y, Liu W, et al. Prostatic Arterial Embolization Treating Moderate-to-Severe Lower Urinary Tract Symptoms Related to Benign Prostate Hyperplasia: A Meta-Analysis. Cardiovasc Intervent Radiol 2017;40:22-32.

52. Pisco JM, Rio Tinto H, Campos Pinheiro L, et al. Embolisation of prostatic arteries as treatment of moderate to severe lower urinary symptoms (LUTS) secondary to benign hyperplasia: results of short- and mid-term followup. Eur Radiol 2013;23:2561-72.

53. Amouyal G, Thiounn N, Pellerin O, et al. Clinical Results After Prostatic Artery Embolization Using the PErFecTED Technique: A Single-Center Study. Cardiovasc Intervent Radiol 2016;39:367-75.
54. Bagla S, Martin CP, van Breda A, et al. Early results from a United States trial of prostatic artery embolization in the treatment of benign prostatic hyperplasia. J Vasc Interv Radiol 2014;25:47-52.

55. Cizman Z, Isaacson A, Burke C. Short- to Midterm Safety and Efficacy of Prostatic Artery Embolization: A Systematic Review. J Vasc Interv Radiol 2016;27:14871493.e1.

56. de Assis AM, Moreira AM, de Paula Rodrigues VC, et al. Prostatic artery embolization for treatment of benign prostatic hyperplasia in patients with prostates> $90 \mathrm{~g}: \mathrm{a}$ prospective single-center study. J Vasc Interv Radiol 2015;26:87-93.

57. Pisco J, Campos Pinheiro L, Bilhim T, et al. Prostatic arterial embolization for benign prostatic hyperplasia: short- and intermediate-term results. Radiology 2013;266:668-77.

58. Wang M, Guo L, Duan F, et al. Prostatic arterial embolization for the treatment of lower urinary tract symptoms caused by benign prostatic hyperplasia: a comparative study of medium- and large-volume prostates. BJU Int 2016;117:155-64.

59. Wang MQ, Guo LP, Zhang GD, et al. Prostatic arterial embolization for the treatment of lower urinary tract symptoms due to large $(>80 \mathrm{~mL})$ benign prostatic hyperplasia: results of midterm follow-up from Chinese population. BMC Urol 2015;15:33.

60. Noor A, Fischman AM. Prostate Artery Embolization as a New Treatment for Benign Prostate Hyperplasia: Contemporary Status in 2016. Curr Urol Rep 2016;17:51.

61. A Pereira J, Bilhim T, Duarte M, et al. Patient selection and counseling before prostatic arterial embolization. Tech Vasc Interv Radiol 2012;15:270-5.

62. Delgal A, Cercueil JP, Koutlidis N, et al. Outcome of transcatheter arterial embolization for bladder and prostate hemorrhage. J Urol 2010;183:1947-53.

63. Giné E, Rovira M, Real I, et al. Successful treatment of severe hemorrhagic cystitis after hemopoietic cell transplantation by selective embolization of the vesical arteries. Bone Marrow Transplant 2003;31:923-5.

64. Han Y, Wu D, Sun A, et al. Selective embolization of the internal iliac arteries for the treatment of severe hemorrhagic cystitis following hematopoietic SCT. Bone Marrow Transplant 2008;41:881-6.

65. Jeong CW, Park YH, Ku JH, et al. Minimally invasive management of postoperative bleeding after radical prostatectomy: transarterial embolization. J Endourol 2010;24:1529-33. 
66. Feuer DS, Ciocca RG, Nackman GB, et al. Endovascular management of ureteroarterial fistula. J Vasc Surg 1999;30:1146-9.

67. Kibrik P, Eisenberg J, Bjurlin MA, et al. Endoureteral coil embolization of an ureteral arterial fistula. Vascular 2017;25:557-60.

68. Kim KR, Shin JH, Song HY, et al. Treatment of high-flow priapism with superselective transcatheter embolization in 27 patients: a multicenter study. J Vasc Interv Radiol 2007;18:1222-6.

69. Savoca G, Pietropaolo F, Scieri F, et al. Sexual function after highly selective embolization of cavernous artery in patients with high flow priapism: long-term follow up. J Urol 2004;172:644-7.

70. Kim KR. Embolization Treatment of High-Flow Priapism. Semin Intervent Radiol 2016;33:177-81.

71. Ciampalini S, Savoca G, Buttazzi L, et al. High-flow priapism: treatment and long-term follow-up. Urology 2002;59:110-3.

72. Sam K, Gahide G, Soulez G, et al. Percutaneous embolization of iatrogenic arterial kidney injuries: safety, efficacy, and impact on blood pressure and renal function. J Vasc Interv Radiol 2011;22:1563-8.

73. Petitpierre F, Cornelis F, Couzi L, et al. Embolization of renal arteries before transplantation in patients with polycystic kidney disease: a single institution long-term experience. Eur Radiol 2015;25:3263-71.

74. Bilhim T, Pisco J, Rio Tinto H, et al. Unilateral versus bilateral prostatic arterial embolization for lower urinary tract symptoms in patients with prostate enlargement.

Cite this article as: Fergus KB, Baradaran N, Tresh A, Conrad $\mathrm{MB}$, Breyer BN. Use of angioembolization in urology: a review. Transl Androl Urol 2018;7(4):535-544. doi: 10.21037/ tau.2018.05.12
Cardiovasc Intervent Radiol 2013;36:403-11.

75. Jacobson AI, Amukele S, Marcovich R, et al. Efficacy and morbidity of therapeutic renal embolization in the spectrum of urologic disease. J Endourol 2003;17:385-91.

76. Andreucci M, Faga T, Pisani A, et al. Acute kidney injury by radiographic contrast media: pathogenesis and prevention. Biomed Res Int 2014;2014:362725.

77. Rundback JH, Nahl D, Yoo V. Contrast-induced nephropathy. J Vasc Surg 2011;54:575-9.

78. Kang X, Hu DY, Li CB, et al. N-acetylcysteine for the prevention of contrast-induced nephropathy in patients with pre-existing renal insufficiency or diabetes: a systematic review and meta-analysis. Ren Fail 2015;37:297-303.

79. Au TH, Bruckner A, Mohiuddin SM, et al. The prevention of contrast-induced nephropathy. Ann Pharmacother 2014;48:1332-42.

80. Hirst A, Dutton S, Wu O, et al. A multi-centre retrospective cohort study comparing the efficacy, safety and cost-effectiveness of hysterectomy and uterine artery embolisation for the treatment of symptomatic uterine fibroids. The HOPEFUL study. Health Technol Assess 2008;12:1-248, iii.

81. Bagla S, Smirniotopoulos J, Orlando J, et al. Cost Analysis of Prostate Artery Embolization (PAE) and Transurethral Resection of the Prostate (TURP) in the Treatment of Benign Prostatic Hyperplasia. Cardiovasc Intervent Radiol 2017;40:1694-7.

82. Bruce PJ, Helmer SD, Harrison PB, et al. Nonsurgical management of blunt splenic injury: is it cost effective? Am J Surg 2011;202:810-5; discussion 815-6. 